\title{
Anemia and iron deficiency among school adolescents: burden, severity, and determinant factors in southwest Ethiopia
}

This article was published in the following Dove Press journal:

Adolescent Health, Medicine and Therapeutics

15 December 2015

Number of times this article has been viewed

\author{
Melkam Tesfaye' \\ Tilahun Yemane ${ }^{2}$ \\ Wondimagegn Adisu ${ }^{2}$ \\ Yaregal Asres ${ }^{2}$ \\ Lealem Gedefaw ${ }^{2}$ \\ 'Department of Clinical Laboratory, \\ Bonga Hospital, Bonga, ${ }^{2}$ Department \\ of Medical Laboratory Science and \\ Pathology, College of Health Sciences, \\ Jimma University, Jimma, Ethiopia
}

Background: Adolescence is the period of most rapid growth second to childhood. The physical and physiological changes that occur in adolescents place a great demand on their nutritional requirements and make them more vulnerable to anemia. Anemia in the adolescence causes reduced physical and mental capacity and diminished concentration in work and educational performance, and also poses a major threat to future safe motherhood in girls. The purpose of this study was to determine the prevalence of anemia and its associated factors among school adolescents in Bonga Town, southwest Ethiopia.

Methods: A cross-sectional study was conducted among 408 school adolescents in Bonga Town, southwest Ethiopia, from March 15, 2014 to May 25, 2014. An interviewer-administered questionnaire was used to collect sociodemographic and other data. A total of $7 \mathrm{~mL}$ of venous blood and $4 \mathrm{~g}$ of stool samples were collected from each study participant. Blood and stool samples were analyzed for hematological and parasitological analyses, respectively. Data were analyzed using SPSS Version 20 software for Windows.

Results: The overall prevalence of anemia was $15.2 \%$ (62/408), of which $83.9 \%$ comprised mild anemia. The proportion of microcytic, hypochromic anemia was 53\% (33/62). Being female (adjusted odds ratio $[\mathrm{AOR}]=3.04,95 \%$ confidence interval $(\mathrm{CI})=1.41-6.57$ ), household size $\geq 5(\mathrm{AOR}=2.58,95 \% \mathrm{CI}=1.11-5.96)$, father's illiteracy $(\mathrm{AOR}=9.03,95 \% \mathrm{CI}=4.29-18.87)$, intestinal parasitic infection ( $\mathrm{AOR}=5.37,95 \% \mathrm{CI}=2.65-10.87$ ), and low body mass index ( $\mathrm{AOR}=2.54,95 \% \mathrm{CI}=1.17-5.51)$ were identified as determinants of anemia among school adolescents.

Conclusion: This study showed that anemia was a mild public health problem in this population. School-based interventions on identified associated factors are important to reduce the burden of anemia among school adolescents.

Keywords: anemia, school adolescents, associated factors, Bonga Town

\section{Introduction}

Anemia is a condition characterized by reduction in the number of red blood cells and/or hemoglobin $(\mathrm{Hb})$ concentration. ${ }^{1}$ Anemia is a global public health problem affecting both developing and developed countries and has major consequences for human health as well as social and economic development. It affects $24.8 \%$ of the world population. ${ }^{2}$ The burden of anemia varies with a person's age, sex, altitude, and pregnancy. ${ }^{1}$ The worldwide prevalence of anemia among adolescents is $15 \%(27 \%$ in developing countries and 6\% in developed countries). ${ }^{3}$ In Ethiopia, the prevalence of anemia among the age group of 15-19-year-old males and females ranged from $2.8 \%$ to $15 \%$ and $9.3 \%$ to $34.8 \%$, respectively. ${ }^{4}$
Correspondence: Lealem Gedefaw Department of Medical Laboratory Science and Pathology, College of Health Sciences, Jimma University, Jimma, Ethiopia

Tel +25l 91302454 I

Email lealem.gedefaw@ju.edu.et 
Causes of anemia in developing countries are multi-factorial, which include nutritional (iron, folate, and vitamin $\mathrm{B}_{12}$ ) deficiencies, infections (such as malaria and intestinal parasitic infection [IPI]), and chronic illness. ${ }^{5}$ Iron deficiency anemia is a condition in which anemia occurs due to lack of available iron to support normal red cell production. ${ }^{6}$ The prevalence of iron deficiency and subsequent anemia increases at the start of adolescence. In girls, this is caused by increased requirements of nutrition for growth, exacerbated a few years later by the onset of menstruation, but subsides for boys. ${ }^{7}$ The physical and physiological changes that occur in adolescents place a great demand on their nutritional requirements and make them more vulnerable to nutritional deficiencies. Adolescents are at high risk of iron deficiency and anemia. This is due to rapid pubertal growth with sharp increase in lean body mass, blood volume, and red cell mass, which increases iron requirements for myoglobin in muscles and $\mathrm{Hb}$ in the blood. Iron requirement increases two- to threefolds from a preadolescent level of $\sim 0.7-0.9 \mathrm{mg}$ iron/ day to as much as $1.37-1.88 \mathrm{mg}$ iron/day in adolescent boys and 1.40-3.27 mg iron/day in adolescent girls. ${ }^{7,8}$ Anemia in adolescence has serious implications for a wide range of outcomes, and nearly all of the functional consequences of iron deficiency are strongly related to the severity of anemia. It causes reduced resistance to infection, impaired physical growth and mental development, and reduced physical fitness, work capacity, and school performance. ${ }^{7,9-11}$

Interventions to reduce the burden of anemia and iron deficiency anemia should address the causatives. Costeffective anemia prevention and control strategies are welldocumented and have the power for their intended objectives in different countries. ${ }^{2,11,12}$ Knowledge of the degree and causes of anemia in adolescence is important, as this is a window of opportunity for school-based interventions to improve adolescent health. There is a scarcity of data on anemia in adolescents living in developing countries in the complex ecologic context of poverty, parasitism, and malnutrition. At all levels, the negative effects of anemia during adolescence justify public health action; unfortunately, because initiatives to prevent anemia commonly target infants, young children, and pregnant and lactating women, and not necessarily adolescents, the needs of adolescents may remain unmet and the consequences of anemia in adolescents continue. But limited data are available on the prevalence of anemia, iron deficiency, and associated factors among adolescents in Ethiopia, particularly in Bonga Town.

Therefore, this study was aimed to determine the prevalence of anemia, iron deficiency, and associated factors among school adolescents in Bonga Town, southwest Ethiopia.

\section{Materials and methods Study area and population}

An institution-based cross-sectional study was conducted among school adolescents in Bonga Town from March 15, 2014 to May 25, 2014. Bonga Town, a town in the Kaffa Zone, is located $466 \mathrm{~km}$ southwest of the capital city, Addis Ababa. It has an average altitude of 1,714 $\mathrm{m}$ above the sea level. The total population of Bonga Town was 28,960, which comprised 14,906 females and $14,054 .{ }^{4}$ Nineteen percent of the total population was adolescents. There were nine governmental schools in Bonga Town administration (three primary, four primary and secondary, and two secondary schools) with a total number of 7,520 students; 5,393 were within the age group of 12-19 years.

\section{Sample size and sampling technique}

The sample size was determined using the single population proportion statistical formula $\left(\mathrm{n}=z(1-\alpha / 2)^{2} \times P(1-p) / d^{2}\right)$. We used $50 \%$ prevalence of anemia among the group because there was no report in the study area, 5\% marginal error, and 95\% confidence level, and $10 \%$ anticipated non-response rate were considered. The final minimum sample size for the study was 422. We included adolescents between 12 years and 19 years who voluntarily participated in the study and excluded school adolescents who had been blood transfused prior to 4 months of data collection, who were on treatments for anemia, and who were pregnant and lactating. Female school adolescents who were married but not using contraceptives and, at the same time, not confirmed for their pregnancy were requested to undergo the urine human chorionic gonadotropin test.

Among eight governmental schools in Bonga Town (Kenteri, Umiti, Millennium, Sheta, Bandra, Barta, B/ Mariam, and Bishaw Woldeyohanis), the first three were not included, since all students were $<12$ years of age. From a total of 7,520 students in Bonga Town enrolled for the academic year 2013/2014, 5,393 were adolescents, all in five schools, of which 1,013 were in Bishaw Woldeyohanis Preparatory School, 758 in B/Mariam Secondary School, 1,875 in Bandra Primary and Secondary School, 1,125 in Sheta Primary and Secondary School, and 622 in Barta Primary and Secondary School. Study participants were selected using a systematic random sampling technique, using each school student's registration details for the academic year as a sampling frame, which included name, age, and sex. The sequence of schools from the first to the last was followed 
by using a lottery method as Bandra, Sheta, B/Mariam, Bishaw Woldeyohanis, and Barta, respectively. Sampling was started from the first grade in all the schools purposively. The constant $K$ was determined by dividing the total study population by the sample size $(K=5,393 / 422=12.7)$. The fifth adolescent student was selected by using a lottery method. The first study participant was the fifth adolescent student in Bandra School, and consecutive study participants were selected at every thirteenth interval.

\section{Data collection methods and instruments Questionnaire-based interview and anthropometric measurement}

Sociodemographic, socioeconomic, and clinical data were collected by trained clinical nurses by using an intervieweradministered questionnaire. Weight and height were taken for each study participant. Height was measured to the nearest $0.1 \mathrm{~cm}$, and weight to the nearest $0.1 \mathrm{~kg}$. Each subject was weighed with light clothing and no foot wear. All the measurements were taken twice; when necessary, any discrepancies were resolved by a third measurement. The mean values were used for data analysis.

\section{Blood collection and analysis}

A total of $4 \mathrm{~mL}$ of anticoagulated ethylenediaminetetraacetic acid and $3 \mathrm{~mL}$ of nonanticoagulated venous blood sample were collected from each study participant using a vacutainer system. Then the samples were transported to the Bonga Hospital laboratory within 2 hours of collection. We determined $\mathrm{Hb}$ concentration, mean corpuscular hemoglobin $(\mathrm{MCH}), \mathrm{MCH}$ concentration, and mean corpuscular volume using CELL-DYN ${ }^{\circledR} 1800$ (Abbott Laboratories, Abbott Park, IL, USA). We prepared both thick and thin blood films for the assessment of hemoparasites and evaluation of red cell morphology. Serum iron was measured by the chromazurol B method ${ }^{13}$ by using a Humaster 80 Chemistry analyzer (Human Diagnostics, Wiesbaden, Germany). Female adolescents older than 12 years and males in the age group of 12-14 years who had an $\mathrm{Hb}$ concentration $<12 \mathrm{~g} / \mathrm{dL}$ and males older than 15 years who had an $\mathrm{Hb}$ concentration $<13 \mathrm{~g} / \mathrm{dL}$ were considered as anemic. Hb values of $11-11.9 \mathrm{~g} / \mathrm{dL}, 8-10.9 \mathrm{~g} / \mathrm{dL}$, and $<8 \mathrm{~g} / \mathrm{dL}$ were categorized as having mild, moderate, and severe anemia, respectively; however, for male adolescents older than 15 years, Hb concentration of 11.0-12.9 g/ $\mathrm{dL}$ indicated mild anemia. ${ }^{1}$ Microcytosis was defined as a mean corpuscular volume value $<80 \mathrm{fL}$, and hypochromia was defined as $\mathrm{MCH}$ concentration value $<32 \mathrm{~g} / \mathrm{dL}$. Iron deficiency was defined as a serum iron concentration
$<59 \mu \mathrm{g} / \mathrm{L}$ for males and $<37 \mu \mathrm{g} / \mathrm{L}$ for females. ${ }^{13} \mathrm{~A}$ body mass index $(\mathrm{BMI})<18.5 \mathrm{~kg} / \mathrm{m}^{2}$ indicates thinness or acute under nutrition, while a BMI $>25.0 \mathrm{~kg} / \mathrm{m}^{2}$ indicates overweight.

\section{Parasitological survey}

Four grams of stool sample was collected from each study participant using clean, wide mouthed, and leak-proof stool cups. Then, we examined stool samples at the data collection site within 10-15 minutes of collection by wet mount preparation. Leftover samples were preserved using 10\% formalin as a preservative and transported to the Bonga Hospital laboratory, where we processed for the formol-ether concentration technique. Both thick and thin blood films were examined for the assessment of hemoparasites.

\section{Quality assurance}

To ensure the quality of data, data collectors were trained and the questionnaire was pretested. All laboratory activities were performed by strictly following manufacturers' instructions and specific standard operating procedures. Quality control samples were used accordingly. All reagents and quality control samples were checked for their expiry date. Laboratory results were recorded on standard report formats according to a unique identification number.

\section{Ethical consideration}

Ethical clearance was obtained from the Jimma University Ethics Review Committee, College of Health Sciences. Permission to conduct the study was obtained from each school director's office. We explained the objectives of the study to each study participant. We obtained written informed consent from 18-year- to 19-year-old study participants and from guardians of $<18$-year-old study participants. In addition, there was an assent section of the consent form for study participants aged $<18$ years old. The blood and stool specimens were used only for the intended purpose, and leftover specimens were discarded according to the national guidelines. All the data were kept confidential, and this was done using a unique code number. Participants confirmed as anemic and having an IPI were treated under the consultation of physicians.

\section{Statistical analysis}

BMI was calculated as weight in kilograms divided by the square of height in meters using Microsoft Office Excel 2007. Adjusted $\mathrm{Hb}$ concentration was calculated as $\mathrm{Hb}=-0.32 \times($ altitude in meters $\times 0.0033)+0.22 \times($ altitude in meters $\times 0.0033)^{2}$ to subtract the adjustment from the measured $\mathrm{Hb}$ concentration at the relevant altitude 
$(1,714 \mathrm{~m}$ above the sea level) to get the sea-level value. Then all data were entered, cleaned, and analyzed using SPSS for Windows Version 20.0 statistical package. Descriptive statistics were used to give a clear picture of background information and determine the prevalence of anemia. Binary logistic regressions were used to identify the candidate variables for multiple logistic regression analysis. All explanatory variables that have been associated with the outcome variable in bivariate analyses at a $25 \%$ level of significance were considered as candidates for backward multiple logistic regression analysis. All variables with $P$-values $<0.05$ were considered as statistically significant.

\section{Results}

\section{Sociodemographic and clinical}

\section{characteristics of study participants}

From the total sample size (422), 408 school adolescents were enrolled in the study ( $96.7 \%$ response rate). Most of the study participants were within the age group of 15-19 years, $67.2 \%(n=274)$. The mean age of the study participants was $15 \pm 2$ years. The male to female ratio of the study participant was $0.85: 1$; the females accounted $54.2 \%(n=221)$. The majority of the study participants' mothers were house wives, $42.4 \%(n=173)$. The family size of study participants ranged from 2 to 11, with an average of 5.8 persons per household, and most of the study participants had a household size of $>5$ (Table 1).

All 408 study participants were examined for intestinal parasites, of whom $32.8 \%(n=134)$ showed positive response for at least one intestinal parasite. A total of six species of intestinal parasites were identified. Ascaris lumbricoides $(48.4 \%, \mathrm{n}=77)$ took the predominant proportion followed by Giardia lamblia $(20.8 \%, \mathrm{n}=33)$, Trichuris trichiura $(13.2 \%$, $\mathrm{n}=21)$, Entamoeba histolytica/dispar $(8.8 \%, \mathrm{n}=14)$, Hook worms $(6.3 \%, \mathrm{n}=10)$, and Hymenolepis nana $(2.5 \%, \mathrm{n}=4)$. A microscopic examination of blood films revealed that no hemoparasite was found.

Table I Association of anemia with sociodemographic and clinical factors among school adolescents from March I5, 20I4 to May 25, $2014(n=408)$

\begin{tabular}{|c|c|c|c|c|c|}
\hline \multirow[t]{2}{*}{ Variables } & \multirow[t]{2}{*}{ Categories } & \multicolumn{2}{|l|}{ Anemia } & \multirow[t]{2}{*}{ COR $(95 \% \mathrm{CI})$} & \multirow[t]{2}{*}{$P$-value } \\
\hline & & Yes (\%) & No (\%) & & \\
\hline \multirow[t]{2}{*}{ Sex } & Male & $16(9.4)$ & I54 (90.6) & 1 & \\
\hline & Female & $46(19.3)$ & $192(80.7)$ & $2.31(1.26,4.23)$ & $0.007^{\mathrm{a}}$ \\
\hline \multirow[t]{2}{*}{ Age } & $12-14$ & $22(16.4)$ & $112(83.6)$ & $1.15(0.65,2.03)$ & 0.631 \\
\hline & $15-19$ & $40(14.6)$ & $234(85.4)$ & I & \\
\hline \multirow[t]{4}{*}{ Mothers' occupation } & House wife & $22(12.7)$ & I5I (87.3) & $0.80(0.39,1.65)$ & 0.549 \\
\hline & Farmer & $10(14.7)$ & $58(85.3)$ & $0.95(0.39,2.29)$ & 0.906 \\
\hline & Merchant & $16(21.1)$ & $60(78.9)$ & $1.47(0.66,2.24)$ & 0.344 \\
\hline & Employed & $14(15.4)$ & $77(84.6)$ & 1 & \\
\hline \multirow[t]{4}{*}{ Fathers' occupation } & Daily worker & $17(22.4)$ & $59(77.6)$ & $2.86(1.15,7.09)$ & $0.024^{\mathrm{a}}$ \\
\hline & Farmer & $7(30.4)$ & $16(69.6)$ & $5.10(1.51,17.26)$ & $0.009^{a}$ \\
\hline & Merchant & $13(10.3)$ & $113(89.7)$ & $0.84(0.49,3.69)$ & 0.569 \\
\hline & Employed & $25(13.7)$ & $158(86.3)$ & 1 & \\
\hline \multirow[t]{4}{*}{ Fathers' education } & No education & $33(38.8)$ & $52(6 \mid .2)$ & $9.18(4.10,20.49)$ & $<0.00 \mathrm{I}^{\mathrm{a}}$ \\
\hline & Primary & $14(12.3)$ & $100(87.7)$ & $2.02(0.84,4.86)$ & 0.116 \\
\hline & Secondary & $6(8.6)$ & $64(91.4)$ & $1.35(0.46,3.97)$ & 0.181 \\
\hline & Above & $9(6.5)$ & $130(93.5)$ & 1 & \\
\hline \multirow[t]{4}{*}{ Mothers' education } & No education & $19(20.9)$ & $72(79.1)$ & $1.47(0.66,3.24)$ & 0.344 \\
\hline & Primary & $22(12.7)$ & I5I (87.3) & I.25 $(0.39,2.29)$ & 0.906 \\
\hline & Secondary & $10(14.7)$ & $58(85.3)$ & I.0I $(0.39,1.65)$ & 0.549 \\
\hline & Above & II (I4.5) & $65(85.5)$ & 1 & \\
\hline \multirow[t]{3}{*}{ Monthly income in ETB } & $<500$ & $12(16.0)$ & $63(84.0)$ & $\mathrm{I} .09(0.5 \mathrm{I}, 2.35)$ & 0.824 \\
\hline & $500-1,000$ & $28(15.1)$ & $157(84.9)$ & $1.02(0.56,1.87)$ & 0.945 \\
\hline & $>1,000$ & $22(14.9)$ & $126(85.1)$ & 1 & \\
\hline \multirow[t]{2}{*}{ Family size } & $<5$ & $10(6.9)$ & $134(93.1)$ & 1 & \\
\hline & $\geq 5$ & $52(19.7)$ & $212(80.3)$ & $3.29(1.62,6.69)$ & $0.00 I^{\mathrm{a}}$ \\
\hline \multirow[t]{2}{*}{ IPI } & Positive & $37(27.6)$ & $97(72.4)$ & $3.79(2.17,6.65)$ & $<0.00 I^{\mathrm{a}}$ \\
\hline & Negative & $25(9.1)$ & 249 (90.9) & I & \\
\hline
\end{tabular}

Note: aStatistically significant factors.

Abbreviations: COR, crude odds ratio; $\mathrm{Cl}$, confidence interval; ETB, Ethiopian Birr; IPI, intestinal parasite infection. 


\section{Dietary and nutritional characteristics of adolescents}

Eating habit sources of heme iron and enhancers and inhibitors of iron absorption were assessed among all study participants. The majority, $90.4 \%$ ( $n=369)$, of the study participants ate meat/ poultry less than two times per week and $78.9 \%(n=322)$ took citrus fruits less than two times per week. Most of the study participants, 92.2\% ( $\mathrm{n}=376)$, responded that they drink tea/ coffee within 30 minutes after meal (Table 1).

\section{Prevalence, severity, and type of anemia}

The overall prevalence of anemia was $15.2 \%(n=62)$. The prevalence was higher in female (19.3\%) than male $(9.4 \%)$ adolescents. From the overall number of anemic adolescents, $74.2 \%(n=46)$ were females, and the prevalence of anemia among females who attained menarche was $26.4 \%$ (Table 2). Most of the anemic adolescents had mild anemia (83.9\%), followed by moderate $(12.9 \%)$ and severe anemia (3.2\%). From the total number of anemic adolescents, $53 \%(n=33), 40 \%(n=25)$, and $7 \%(n=4)$ had microcytic hypochromic, normocytic normochromic, and macrocytic normochromic anemia, respectively. More than $72 \%$ of anemic adolescents had low serum iron concentration (Figure 1).

\section{Independent predictors of anemia among study participants}

Six explanatory candidate variables from backward multiple logistic regression analysis were found to be independent predictors of anemia among school adolescents. Their corresponding adjusted odds ratios are presented in Table 3.

\section{Discussion}

The aim of this study was to determine the prevalence of anemia and associated factors of anemia among school adolescents in Bong Town, southwest Ethiopia. Four hundred and eight randomly selected representative school adolescents were involved in this study. Approximately, one in six school adolescents were anemic in our study. The overall prevalence of anemia was $15.2 \%$, indicating mild public health importance. This showed that anemia was indeed a public health problem among the adolescents in the area. Multivariate analysis identified sex, family size, father's educational status, IPI, and BMI as predictors of anemia among adolescents in this study.

The 2011 Ethiopia Demographic and Health Survey reported that the prevalence of anemia among adolescents in the age range of 15-19 years was $13.4 \%$. For the same age group, the prevalence of anemia was $9.4 \%$ in Southern Nation's Nationalities and Peoples Region of Ethiopia. ${ }^{4}$ This variation might be due to the difference in the study population that a larger age range of study participants (12-19 years) were included in this study. The prevalence of anemia in this study was higher than studies among adolescents in Turkey $(5.6 \%)^{3}$ and in Shimla, India $(13.1 \%) .{ }^{14}$ This variation might be due to age group differences as 12-16-year- and 10-19year-old adolescents were included in these two studies, respectively. The other reason might be due to the high

Table 2 Association of anemia with nutritional and reproductive health-related factors among school adolescents in southwest Ethiopia from March 15, 2014 to May 25, 2014

\begin{tabular}{|c|c|c|c|c|c|}
\hline \multirow[t]{2}{*}{ Variables } & \multirow[t]{2}{*}{ Categories } & \multicolumn{2}{|l|}{ Anemia } & \multirow[t]{2}{*}{ COR $(95 \% \mathrm{Cl})$} & \multirow[t]{2}{*}{$P$-value } \\
\hline & & Yes (\%) & No (\%) & & \\
\hline \multirow[t]{2}{*}{ Meat, poultry eating/week } & $\geq 2$ times/week & $5(12.8)$ & $34(87.2)$ & 1 & \\
\hline & $<2$ times/week & $57(15.4)$ & $312(84.6)$ & $\mathrm{I} .24(0.47,3.3 \mathrm{I})$ & 0.664 \\
\hline \multirow[t]{2}{*}{ Eating citrus fruits } & $>2$ times/week & $15(17.4)$ & 7I (82.6) & 1 & 0.514 \\
\hline & $\leq 2$ times/week & $47(14.6)$ & $275(85.4)$ & $1.25(0.65,2.34)$ & \\
\hline \multirow[t]{2}{*}{ Tea/coffee after meal } & Within 30 minutes after meal & $58(15.4)$ & $318(84.6)$ & $1.28(0.43,3.37)$ & 0.659 \\
\hline & $>30$ minutes after meal & $4(12.5)$ & $28(87.5)$ & I & \\
\hline \multirow[t]{2}{*}{ Body mass index $\left(\mathrm{kg} / \mathrm{m}^{2}\right)$} & $<18.5$ & $23(25.8)$ & $66(74.2)$ & $2.50(1.40,4.47)$ & $0.002^{\mathrm{a}}$ \\
\hline & $\geq 18.5$ & $39(12.2)$ & $280(87.8)$ & I & \\
\hline \multirow[t]{2}{*}{ Status of menarche } & Attained & $29(26.4)$ & 81 (73.6) & $2.34(1.20,4.54)$ & $0.012^{\mathrm{a}}$ \\
\hline & Not attained & $17(13.3)$ & III (86.7) & I & \\
\hline \multirow[t]{2}{*}{ Length of blood flow in each menses } & $\leq 5$ days & $26(24.8)$ & $79(75.2)$ & & $0.113^{b}$ \\
\hline & $>5$ days & $3(60.0)$ & $2(40.0)$ & & \\
\hline \multirow[t]{2}{*}{ Sanitary pad usage per day } & $<3$ & $27(25.0)$ & $8 \mathrm{I}(75.0)$ & & $0.068^{\mathrm{b}}$ \\
\hline & $\geq 3$ & $2(100.0)$ & 0 & & \\
\hline
\end{tabular}

Notes: aStatistically significant factor; 'P -value for Fisher's exact test. Abbreviations: $\mathrm{COR}$, crude odds ratio; $\mathrm{Cl}$, confidence interval. 


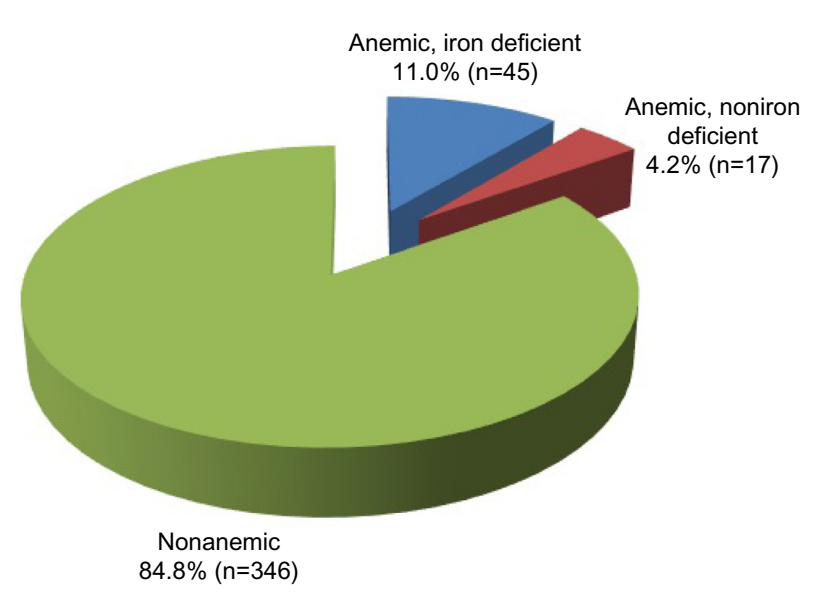

Figure I Serum iron concentration among anemic school adolescents in southwest Ethiopia, from March 15, 2014 to May 25, 2014.

prevalence of IPI in our study, difference in Hb cutoff value, and study population.

However, prevalence of anemia in this study was much lower than studies conducted in Nepal (65\%), Wardha (59.8\%), and Cote d'Ivoire (53.1\%). ${ }^{15-17}$ The lower prevalence of anemia in this study might be due to the variation in geographical area and study participants. This study was school based and was carried out in an urban population, which might decrease the prevalence in this study.

It was indicated that among anemic adolescents, the proportion of mild anemia was high $(83.9 \%)$, followed by moderate anemia (12.9\%) and severe anemia (3.2\%). This finding was in parallel with studies done in Pondicherry ${ }^{18}$

Table 3 Independent predictors of anemia from a multivariate logistic regression model among school adolescents in southwest Ethiopia from March 15, 2014 to May 25, 2014 ( $n=408)$

\begin{tabular}{|c|c|c|c|}
\hline Variables & Category & AOR (95\% Cl) & $P$-value \\
\hline \multirow[t]{2}{*}{ Sex } & Female & $3.04(I .4 I, 6.57)$ & $0.005^{a}$ \\
\hline & Male & I & \\
\hline \multirow[t]{2}{*}{ Household size } & $<5$ & I & \\
\hline & $\geq 5$ & $2.58(1.11,5.96)$ & $0.027^{a}$ \\
\hline Father's & Illiterate & $9.03(4.29,18.87)$ & $<0.00 I^{\mathrm{a}}$ \\
\hline \multirow[t]{3}{*}{ educational status } & Primary & $5.34(1.85,10.42)$ & $0.002^{\mathrm{a}}$ \\
\hline & Secondary & $2.86(0.87,6.42)$ & 0.085 \\
\hline & More than secondary & 1 & \\
\hline Father's & Daily worker & $2.11(1.94,5.32)$ & $0.04 \mathrm{I}^{\mathrm{a}}$ \\
\hline \multirow[t]{3}{*}{ occupation } & Farmer & $1.67(0.39,3.12)$ & 0.530 \\
\hline & Merchant & $1.13(0.5 \mathrm{I}, 2.34)$ & 0.068 \\
\hline & Employee & $\mathrm{I}$ & \\
\hline \multirow[t]{2}{*}{ IPI } & Negative & $5.37(2.65,10.87)$ & $<0.00 I^{\mathrm{a}}$ \\
\hline & Positive & 1 & \\
\hline Body mass index & $<18.5$ & $2.54(I .17,5.5 I)$ & $0.018^{a}$ \\
\hline$\left(\mathrm{kg} / \mathrm{m}^{2}\right)$ & $\geq 18.5$ & I & \\
\hline
\end{tabular}

Note: aStatistically significant factor.

Abbreviations: $\mathrm{AOR}$, adjusted odds ratio; $\mathrm{Cl}$, confidence interval; IPI, intestinal parasitic infection. and Shimla of India ${ }^{19}$ and IBSY (Indira Bal Swasthya Yojna) of northern India. ${ }^{20}$ However, our study is different from the study performed in Eastern Sudan where 66.8\% had moderate anemia and $12.1 \%$ had severe anemia. ${ }^{21}$ The reason for this variation might be increased nutritional deficiency and difference in study participants. The study in Eastern Sudan reported increased deficiency of micronutrients, such as iron, folate, copper, and zinc, which contributed to the etiology of anemia, and the study participants were mainly adolescent girls. Using altitude-adjusted $\mathrm{Hb}$ concentration in our study might be the other reason for this variation.

From the anemic adolescents, more than half of them had microcytic hypochromic anemia (53\%), followed by normocytic normochromic anemia $(40 \%)$ and macrocytic normochromic anemia (7\%). The reason for the high percentage of microcytic hypochromic anemia might be due to iron deficiency in adolescents because of rapid growth, hormonal change, and starting of menstrual period in girls. Our study findings indicated that female adolescents were 3.04 times more likely to be anemic than male adolescents. This finding was in line with similar studies carried out in Turkey ${ }^{3}$ and among Black and Spanish American adolescents. ${ }^{12}$ Scientific evidence suggests that physical and physiological changes that occur in adolescent girls place a great demand on their nutritional requirements and make them more vulnerable to nutritional deficiencies. Specifically, the increase in the lean body mass, the expansion of the total blood volume, and the onset of menstruation translate into a significant increase in girls' iron requirements, making them more susceptible to anemia. ${ }^{22}$

Fathers' educational status was significantly associated with the prevalence of anemia among school adolescents in this study. School adolescents who had illiterate fathers were 9.03 times more likely to be anemic as compared to school adolescents who had fathers who were literate above the secondary level. This might be due to the reason that a father who is educated is able to make informed decisions about his own family and so for his child as compared to his illiterate counterpart. This is because, in Ethiopia, most of the family's decisions are made by the father and when they are educated, they might have the power to make decisions in matters related to adolescent health and the expected expenses, which had an effect on the anemia prevalence. On the other side, the reason might be that educated fathers are more likely to have well-paid jobs and are also more likely to adopt a healthier dietary behavior.

This study also showed that the prevalence of anemia among school adolescents who had been infected with intestinal parasites was significantly higher compared to those 
noninfected with intestinal parasites. This is in line with a previous similar study. ${ }^{23}$ This might be due to the fact that most identified intestinal parasites have their own contribution on blood loss and/or red cell destruction.

In our study, family size was significantly associated with anemia among school adolescents. School adolescents who had family size of five and more were 2.58 times more likely to be anemic as compared with school adolescents from a family size of less than five. This might be due to the reason that the large size of the family can be related with low care per family member and income constraint to obtain diets with a variety of foods rich in micronutrients such as iron. Our study revealed that the nutritional status was significantly associated with anemia. Undernourished school adolescents who had a low BMI $<18.5 \mathrm{~kg} / \mathrm{m}^{2}$ were 2.54 times more likely to have anemia as compared to those who have a BMI $\geq 18.5 \mathrm{~kg} / \mathrm{m}^{2}$. Although literature indicated that there was an association between the prevalence of anemia among female adolescents with frequency of meat consumption, ${ }^{24}$ no statistical significant association between dietary habits and prevalence of anemia was observed in this study. This could be possibly due to the fact that dietary history was obtained by using 24 hours recall method that was not adequate to bring out the true association between dietary intake and prevalence of anemia. The associations between anemia and malaria, which have been observed in similar studies, were not demonstrated in our study. This was due to the low prevalence in the area and no malaria parasite infection identified in our study.

Although our study tried to determine the prevalence of anemia, serum iron concentrations, and associated factors among school adolescents, it was not without limitation. Owing to the cross-sectional study design used, whether anemia preceded the predisposing factors or the vice versa could not be verified in this study. The level of serum ferritin was not measured in this study, which limits further determination of the prevalence of iron deficiency anemia.

\section{Conclusion}

According to the World Health Organization, ${ }^{2}$ anemia in this study can be considered of mild public health significance; indeed, it was a public health problem among school adolescents in the area. School-based intervention among school adolescents based on identified determinant factors will be very important for the prevention and control of anemia among the group.

\section{Acknowledgments}

The authors would like to thank study participants who provided all relevant information for the study and also biological samples as volunteers. We also extend our gratitude to the data collectors for their efforts.

\section{Author contributions}

MT, WA, LG, and TY conceived the study, participated in the design and data analysis. MT and YA were involved in data acquisition and laboratory work. All authors contributed towards data analysis, drafting and critically revising the paper and agree to be accountable for all aspects of the work. All the authors read and approved the manuscript.

\section{Disclosure}

The authors report no conflicts of interest in this work.

\section{References}

1. De LM, Pena-Rosas RJP, Cusick S, et al. Hemoglobin Concentrations for the Diagnosis of Anemia and Assessment of Severity; Vitamin and Mineral Nutrition Information System. Vol 11. Geneva: World Health Organization; 2011:1.

2. Benoist BD, McLean E, Egli I, et al. Worldwide Prevalence of Anemia 1993-2005. Geneva: World Health Organization; 2008.

3. Balcı YI, Karabulut A, Gürse D, et al. Prevalence and risk factors of anemia among adolescents in Denizli, Turkey. Iran J Pediatr. 2012;22(1): $77-81$.

4. Ethiopia Central Statistical Agency. Ethiopia Demographic and Health Survey 2011; Preliminary Report. Calverton, MD: Addis Ababa Ethiopia: Central Statistics Agency; 2011.

5. Cheesbrough M. District Laboratory Practice in Tropical Countries. 2nd ed. Cambridge: Cambridge University Press; 2005.

6. Ciesla B. Hematology in Practice. 2nd ed. Philadelphia, PA: FA Davis Company; 2011.

7. Usha R. Nutritional Anemia. Boca Raton, FL: CRC press; 2001: $8-12$.

8. World Health Organization. Prevention of Iron Deficiency Anemia in Adolescents: A Role of Weekly Iron and Folic Acid Supplementation. Geneva: World Health Organization; 2011.

9. Beard JL. Iron biology in immune function, muscle metabolism and neuronal functioning. J Nutr. 2001;131:568S-580S.

10. Halterman JS, Kaczorowski JM, Aligne CA, et al. Iron deficiency and cognitive achievement among school-aged children and adolescents in the United States. Pediatrics. 2001;107:1381-1386.

11. Jain M, Chandra S. Correlation between hematological and cognitive profile of anemic and non anemic school age girls. Curr Pediatr Res. 2012;16(2):145-149.

12. Bailey LB, Wagner PA, Christakis GI, et al. Folacin and iron status and hematological findings in Black and Spanish-American adolescents from urban low-income households. Am J Clin Nutr. 1982;35:1023-1032.

13. Photometric Colorimetric Test for Iron with Lipid Clearing Factor (LCF). 2014. Available from: http://www.standard.com.tw/standard/t_standard/ system_manager/tw/products/uploadFile/71/Su-fe(IRON).pdf. Accessed May 01, 2014.

14. Goel S, Gupta B. Low anemia prevalence among adolescents of an urban hilly community. Indian J Community Med. 2007;32(1):67-68.

15. Baral K, Onta S. Prevalence of anemia amongst adolescents in Nepal a community based study in rural and urban areas of Morang District. Nepal Med Coll J. 2009;11(3):179-182.

16. Kaur S, Deshmukh PR, Garg BS. Epidemiological correlates of nutritional anemia in adolescent girls of rural Wardha. Indian J Community Med. 2006;31(4):255-258.

17. Atto V, Bleyere NM, Konan BA, et al. Hematological profile of adolescents in Abidjan (Côte d'Ivoire). Int J Biosci. 2012;2(6):1-12. 
18. Saratha A, Singh Z, Datta SS, et al. Prevalence of anemia among young adult female students in a medical teaching institution in Pondicherry. Indian J Matern Child Health. 2010;12(4):1-8.

19. Gupta A, Parashar A, Sharma ATD. Anemia among adolescent girls in Shimla Hills of north India: does BMI and onset of menarche have a role. Indian J Med Sci. 2012;66(5):126-130.

20. Verma R, Kharb M, Yadav SP, et al. Prevalence of anemia among adolescents under ibsy in rural block of a district of northern India. Int $J$ Soc Sci Interdiscip Res. 2013;2(9):95-106.

21. Abdelrahim II, Mahgoub HM, Mohamed AA, et al. Anemia, folate, zinc and copper deficiencies among adolescent schoolgirls in Eastern Sudan. Biol Trace Elem Res. 2009;132:60-66.
22. The United Nations Children's Fund. The Adolescent Girls Anemia Control Programme: Breaking the Inter-Generational Cycle of Under Nutrition in India with a Focus on Adolescent Girls. New York, NY: The United Nations Children's Fund; 2011.

23. Leenstra T, Kariuki S, Kurtis J, et al. Prevalence and severity of anemia and iron deficiency: cross-sectional studies in adolescent schoolgirls in western Kenya. Eur J Clin Nutr. 2004;58:681-691.

24. Alaofe H, Zee J, Dossa R, et al. Iron status of adolescent girls from two boarding schools in southern Benin. Public Health Nutr. 2008;11(7): 737-746.

\section{Publish your work in this journal}

Adolescent Health, Medicine and Therapeutics is an international, peer-reviewed, open access journal focusing on health, pathology, and treatment issues specific to the adolescent age group. All aspects of health maintenance, preventative measures and disease treatment interventions are addressed within the journal and practitioners from all disciplines are invited to submit their work as well as healthcare researchers and patient support groups.. The manuscript management system is completely online and includes a very quick and fair peerreview system. Visit http://www.dovepress.com/testimonials.php to read real quotes from published authors.

Submit your manuscript here: http://www.dovepress.com/adolescent-health-medicine-and-therapeutics-journal 